
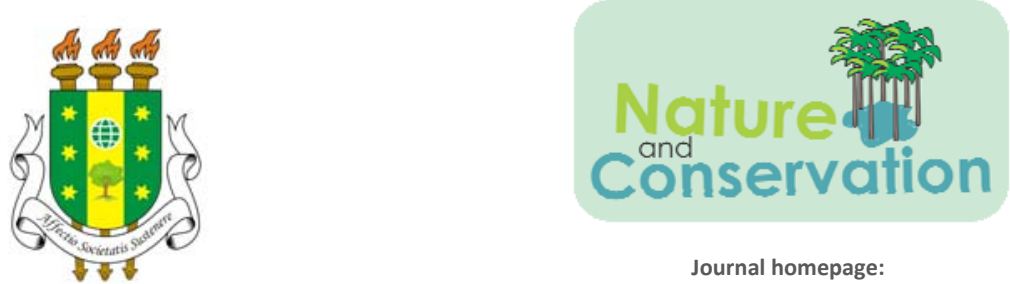

Journal homepage:

www.arvore.org.br/seer

\section{O TURISMO VIRTUAL DE CAVERNAS COMO INSTRUMENTO DIDÁTICO-INCLUSIVO}

\section{RESUMO}

Este trabalho teve como objetivo geral construir um recurso de acessibilidade, através de CD-ROM didático, que permite o turismo virtual a uma das cavernas de Sergipe, a Toca da Raposa, localizada no município de Simão Dias. O CD-ROM foi desenvolvido com uma linguagem clara e acessível, e conta com imagens imersivas que levam um pouco da realidade do ambiente proposto a qualquer pessoa que tenha acesso digital. Dessa forma, diante das características intrínsecas às cavernas de Sergipe (como presença de desníveis, obstáculos, condutos estreitos e tetos baixos) e ausência de plano de manejo, a construção desse material complementar é uma ferramenta importante para a acessibilidade do espeleoturismo por pessoas com necessidades especiais, principalmente as com mobilidade reduzida.

PALAVRAS-CHAVE: Cavernas de Sergipe; Espeleologia; Acessibilidade; Espeleoturismo Virtual.

\section{THE VIRTUAL TOURISM IN CAVES AS A DIDATIC- INCLUSIVE INSTRUMENT}

\section{ABSTRACT}

This work aims to make an accessibility resource, via didactic CD-ROM, which allows a virtual tour through one of the caves of Sergipe, Toca da Raposa, located in the municipality of Simão Dias. The CD-ROM was developed with a clear and accessible language, and includes immersive images that bring some of the environment's reality to anyone who has digital access. Thus, given the intrinsic characteristics of Sergipe's caves (such as the presence of drops and slopes, obstacles, narrow conducts and low ceilings) and absence of management plan, this supplementary material becomes an important tool for speleotourism accessibility, especially by people with reduced mobility.

KEYWORDS: Caves of Sergipe; Speleology; Acessibility; Virtual Speleotourism.
Nature and Conservation,

Aquidabã, v.6, n.2, Mai, Jun, Jul, Ago, Set, Out 2013.

\section{ISSN 2318-2881}

\section{SECTION: Articles}

TOPIC: Espeleoturismo

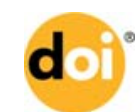

DOI: 10.6008/ESS2318-2881.2013.002.0008

Rubiana Passos Custódio

Universidade Federal de Sergipe, Brasil

http://lattes.cnpq.br/5007245819542749

rubiana.passos@gmail.com

Mário André Trindade Dantas

Universidade Federal de Sergipe, Brasil http://lattes.cnpq.br/2337213908856661 matdantas@yahoo.com.br

Ana Paula do Nascimento Prata Universidade Federal de Sergipe, Brasil http://lattes.cnpq.br/3621697015808240 apprata@gmail.com

\section{Christiane Ramos Donato}

Universidade Federal de Sergipe, Brasil http://lattes.cnpq.br/1035573410272594 christianecrd@yahoo.com.br

Leonardo Morato Duarte Universidade Federal da Bahia, Brasil http://lattes.cnpq.br/2121822400504249 gepaleo@gmail.com

Received: 14/05/2013

Approved: 01/10/2013

Reviewed anonymously in the process of blind peer.

\section{Referencing this:}

CUSTÓDIO, R. P.; DANTAS, M. A. T.; PRATA, A. P. N.; DONATO, C. R.; MORATO, L. O turismo virtual de cavernas como instrumento didático-inclusivo. Nature and Conservation, Aquidabã, v.6, n.2, p.70-84, 2013. DOI: http://dx.doi.org/10.6008/ESS23182881.2013.002.0008 


\section{INTRODUÇÃO}

A acessibilidade é um direito conquistado e instituído pela legislação brasileira em que salvaguarda modificações estruturais que possibilitem o acesso a informações, bens e serviços por toda a população, inclusive partes do público que necessitem de adaptações para consumir ou acessar algo (BRASIL, 1989; 2000; 2004). Atualmente, com o avanço da tecnologia, o computador se tornou uma ferramenta corriqueira, e pode ser utilizado como um meio viável para a acessibilidade.

Vários recursos digitais podem ser utilizados para desenvolver a aprendizagem conceitual, ao mesmo tempo em que entretém, o CD-ROM é um deles. Com armazenamento de informação audiovisual, que ao se somar com diversos aplicativos, poderá ser utilizado para fins didáticos e de inclusão, principalmente ao contar com material interativo, em que o visitante pode utilizá-lo de acordo com o seu tempo de aprendizagem. Além disso, o CD-ROM possui boa relação custobenefício e pode ser amplamente distribuído.

Em nosso contexto específico, uma das várias possibilidades de usar esse artifício tecnológico é através de cursos de Educação Ambiental voltados para a Espeleologia, principalmente para auxiliar o conhecimento e a visualização sobre geo e biodiversidade encontrada nas cavernas. No caso de Sergipe, nenhuma das cavidades registradas possui plano de manejo, mesmo as que já são utilizadas como cavernas turísticas ou de fins religiosos, como a Gruta da Pedra Furada, no município de Laranjeiras (DONATO, 2011). Diante desse pressuposto, é imprescindível divulgar essa ciência, pois ela estuda as cavernas, desde a sua gênese e evolução, passando pela compreensão do seu ambiente físico, químico e biológico, assim como também dos meios e técnicas que são próprias ao seu estudo.

Nessa perspectiva, o objetivo geral desse trabalho foi construir um recurso audiovisual que permita uma "visita virtual" a uma caverna. Para tanto, foi necessário conhecer as características internas da caverna escolhida, seus espeleotemas, os tipos de formações e a fauna; obter fotografias que enfatizassem os principais aspectos da cavidade, destacando-se imagens panorâmicas em QuickTime Virtual Reality (QTVR) e estereofotográficas; e, por fim, produzir o CD-ROM com a apresentação da caverna.

É especialmente a captação de imagens panorâmicas em QuickTime Virtual Reality (QTVR) e estereofotográficas (3D), aliadas à produção do CD-ROM, que possibilitam que esse ambiente seja imersivo, e seja viável o turismo virtual. A partir da produção e divulgação dessas fotografias, permite-se levar a riqueza que existe nas cavernas a um número considerável de grupos na sociedade, destacando-se a inclusão daqueles que, por quaisquer motivos, normalmente não teriam acesso ao meio subterrâneo (MORATO, 2009). Pode ser o caso das pessoas com necessidades especiais (PNE's), os idosos, e mesmo aqueles que têm aversão a ambientes fechados. 


\section{REFERENCIAL TEÓRICO}

\section{Espeleologia, Educação \& Turismo}

A definição de Espeleologia vem do grego spelation, que significa caverna e logos, estudo. O termo foi apresentado pelo historiador francês Riviere, em 1890, tendo Louis de Nussac, em 1892, proposto o termo "mais simplificado" de speologia que chegou a ser adotado principalmente pelos estudiosos da fauna cavernícola. Esse termo, no entanto, foi posteriormente proscrito, pois, derivado do grego speos (“minas, tumbas, escavações artificiais”), era etimologicamente errado (LINO, 2001).

Ela constitui-se numa disciplina consagrada ao estudo das cavernas, desde a sua gênese e evolução, passando pela compreensão do seu meio físico, químico e biológico, assim como também dos meios e técnicas que são próprias ao seu estudo (FERREIRA \& MARTINS, 2001; KARNOPP et al., 2007).

Desde a Pré-história a Espeleologia está presente na vida humana, uma vez que as cavernas na pré-história constituíram-se como um dos primeiros abrigos do homem e seus antigos santuários, onde o profano e o sagrado podiam conviver integrados (LINO, 2001; RODRIGUES, 2007; KARNOPP et al, 2007). Todo o acervo de pinturas rupestres já encontradas nestes locais constitui por si só, prova da ocupação destes valiosos "apartamentos" naturais (KARNOPP et al, 2007).

A maioria das cavernas forma-se em um complexo de rochas sedimentares, em constante modificação, denominado carste. A infiltração de água dissolve lentamente essas rochas (os tipos principais são calcário e dolomito) e esculpe variadas feições internas, gerando diferentes tipos de cavernas. Tais formações geológicas constituem ambientes especiais, sobretudo pela fauna peculiar que as habita (FERREIRA \& MARTINS, 2001).

As distribuições espaciais e populacionais de animais no interior das cavernas são definidas pela ausência ou não de luminosidade, bem como pela não existência de vegetais superiores no interior das mesmas (KARNOPP et al, 2007).

Com relação ao estudo dos ecossistemas, nos últimos anos a relação entre o meio ambiente e seres vivos existentes nos ecossistemas cavernícolas, assim como as interações entre estes elementos bióticos com os abióticos vem sendo estudadas, pela Bioespeleologia (DONATO \& DANTAS, 2009). Esta área de pesquisa está em expansão no Brasil, devido a uma significativa descoberta de seres vivos endêmicos em determinadas cavernas, os quais são fontes de apoio para diversas teorias da Ecologia e Evolução (LINO, 2001).

As comunidades cavernícolas são, em muitos aspectos, bastante peculiares. Existem animais chamados de Troglóbios, que são encontrados exclusivamente nesses ambientes cavernícolas. Os mesmos possuem várias características que lhes garantem sobreviver a este ambiente, porém os transforma em prisioneiros nesse mundo, pois não conseguem se perpetuar 
no ambiente externo (LINO, 2001). Por isso, quaisquer impactos nesses ambientes podem ser bem mais prejudiciais a esses organismos que os ocorridos em sistemas externos (FERREIRA \& MARTINS, 2001).

No Estado de Sergipe, Santana et al (2010) verificaram 29 indicações sobre a existência de cavernas, destas 24 catalogadas junto a Sociedade Brasileira de Espeleologia, entre as mais de 5.695 cavidades já catalogadas no país.

Em Sergipe, os estudos voltados a Espeleologia são recentes, se concentrando principalmente com a fauna de invertebrados (e.g. SANTANA et al, 2009, 2010) e vertebrados cavernícolas (e.g. FERREIRA et al, 2009; DANTAS \& DONATO, 2011).

Tabela 1: Cavernas do Estado de Sergipe.

\begin{tabular}{ccc}
\hline $\mathbf{N}^{\circ}$ SBE & Nome da Caverna & Município \\
\hline 01 & Casa de Pedra & Itabaiana \\
12 & Itabaiana & Divina Pastora \\
10 & Caverna do Urubu & Maruim \\
06 & Gruta da Pedra Branca & Laranjeiras \\
18 & Gruta da Pedra Furada II & Laranjeiras \\
17 & Gruta Raposinha & Laranjeiras \\
19 & Gruta dos Órixas & Laranjeiras \\
07 & Gruta da Pedra Furada & Laranjeiras \\
13 & Gruta da Janela & Laranjeiras \\
05 & Gruta da Raposa & Laranjeiras \\
15 & Gruta da Matriana & Laranjeiras \\
- & Pseudomatriana & Laranjeiras \\
03 & Caverna dos Aventureiros & Laranjeiras \\
- & Gruta do Tramandaí & Japaratuba \\
- & Caverna Casa do Cabloco & São Domingos \\
11 & Gruta da Miaba & São Domingos \\
09 & Toca da Arara & Lagarto \\
08 & Caverna da Fumaça & Simão Dias \\
16 & Abismo de Simão Dias & Simão Dias \\
21 & Toca da Raposa & Simão Dias \\
14 & Furna do Tonho & Simão Dias \\
20 & Furna do Bié & Simão Dias \\
& Furna do Lixo & Simão Dias \\
\hline
\end{tabular}

É importante fomentar a Espeleologia como área do conhecimento e da promoção dos recursos naturais, pois ela objetiva de forma geral o uso sustentável do ambiente cavernícola através de mecanismos que efetivamente contribuam para a conservação deste (MARRA, 2001 citado por RODRIGUES, 2007).

A Espeleologia também pode se tornar uma ferramenta eficaz para a educação no ensino fundamental (RODRIGUES, 2007), pois nesse período as crianças com suas atividades visam conquistar o mundo (LIEVEGOED, 2001 citado por RODRIGUES, 2007). Lievegoed (2001) verificou que nesta faixa etária é importante se realizar trabalhos pedagógicos a partir de excursões pela natureza. A visitação de cavernas mostra-se também muito importante nas praticas pedagógicas de campo, para os Ensinos Fundamental, Médio e Superior (MARRA, 2001 citado por FERREIRA et al, 2008).

Além disso, Morgado et al. (1996 citado por FERREIRA et al., 2008) mencionam a importância da utilização do conhecimento informal dos alunos sobre as cavernas na elaboração de práticas que visem a utilização dos ambientes subterrâneas como base para o ensino de 
disciplinas do Ensino Fundamental e Médio. Inúmeras associações podem ser realizadas entre os processos ocorrentes em cavernas com conteúdos de diversas disciplinas como História, Geografia, Biologia, Química e Física (FERREIRA et al., 2008).

Em contrapartida a inserção da Espeleologia no ensino de Ciências e Biologia, existe a possibilidade dela também ser inserida através do turismo. Por volta do século XIX várias cavernas começaram a ser visitadas pelo público. No Brasil as cavernas de cunho religioso foram as primeiras a receber um número significativo de visitantes atraídos mais pela fé do que pela beleza estética (KARNOPP et al., 2007). Inúmeras cavernas brasileiras foram transformadas em santuários, especialmente na região central do país, dentre as mais visitas estão a Lapa do Bom Jesus, a Gruta Mangabeira e a Gruta dos Brejões, na Bahia e a Terra Ronca em Goiás, com festas e romarias anuais (LINO, 2001).

Há no país, registradas na Sociedade Brasileira de Espeleologia (SBE), em torno de três mil cavernas, mas a própria SBE estima que isso representa apenas $5 \%$ do patrimônio espeleológico nacional. Existiriam, portanto, cerca de 60 mil cavidades no território nacional, a grande maioria ainda desconhecida. Das três mil cavernas conhecidas, cerca de 300 foram estudadas do ponto de vista biológico, mas na maioria dos casos esses estudos restringiram-se a levantamentos da fauna (FERREIRA \& MARTINS, 2001).

Nos últimos anos, segundo Ferreira et al. (2008) os estímulos à visitação de cavernas no Brasil têm crescido consideravelmente. Existem incentivos do governo, do meio acadêmico e da sociedade, no intuito de promover uma maior difusão das atividades turísticas no ambiente de cavernas em todo Brasil.

Esses ambientes se distribuem por quase todo o país, porém, uma pequena parcela é explorada turisticamente. As mesmas são carentes de uma infraestrutura que permita uma visitação em massa, o que evidencia a falta de um planejamento prévio de melhor qualidade, que impede que o ecoturismo aconteça com real impacto educacional (KARNOPP et al., 2007). Atualmente existem no Brasil mais de cinquenta cavernas com turismo regular, incluindo-se aquelas de cunho religioso (LINO, 2001).

Como componentes do relevo cárstico, as cavidades naturais subterrâneas possuem inúmeras características bióticas e abióticas que as fazem atrativos ao uso antrópico (FERREIRA et al., 2008).

Uma das características atrativas das cavidades naturais são os espeleotemas, que são formados por deposições minerais em cavernas formadas basicamente por processos químicos de dissolução e precipitação, são eles em formas de estalactites, estalagmites, colunas, flores de pedra e uma infinidade de tipos, que recobrem os tetos, pisos e paredes das cavernas, causando a admiração dos visitantes e frequentemente intrigando os pesquisadores (LINO, 2001).

Essas formações ornamentam as cavidades, aumentando seu potencial turístico e por vezes religioso, dada a semelhança, no imaginário popular, de alguns espeleotemas com imagens 
sacras ou zoomórficas. A riqueza em espeleotemas coloca várias cavernas brasileiras entre as mais belas de todo o mundo (KARNOPP et al., 2007).

O turismo tem grande potencial econômico e capacidade de gerar renda e emprego nas localidades onde é desenvolvido e o espeleoturismo tem sido visto como uma alternativa viável na utilização dos recursos naturais (DONATO \& RIBEIRO, 2011). Porém o espeleoturismo ainda é um campo recente de estudos dentro do espectro de possibilidades de planejamento, manejo e gestão do turismo em áreas naturais (LOBO \& MORETTI, 2009).

As cavernas são, portanto, interessantes locais de visitação, uma vez que comportam belezas que fascinam o homem. Constituem-se assim numa forma de turismo de alto potencial educativo desde que realizado de maneira adequada. Torna-se evidente que as mesmas como instrumento de visitação são nichos pertencentes ao Ecoturismo, uma vez que o mesmo trata de uma modalidade do turismo cujos objetivos são a preservação e conservação do patrimônio ecológico, ou seja, a prática turística que tem por finalidade a implementação do uso racional do ambiente visitado (KARNOPP et al., 2007).

Porém, o turismo pode ser responsável pela entrada de inúmeros materiais estranhos ao ambiente das cavernas, o que poderia ocasionar um forte desequilíbrio em seu ecossistema. Além disso, todas as instalações feitas nesses ambientes a fim de proporcionar a visitação, como escadas e iluminação artificial, também influenciam para o desequilíbrio ecológico interno, razão pela qual elas somente poderão ser efetuadas após um estudo prévio do impacto ambiental que poderiam causar (KARNOPP et al., 2007)

Os impactos devido à visitação desordenada e ocasional através do turismo irregular existem o fato de deixar resto de carbureto (utilizado para queimar produzindo luz) dentro das cavernas; gerar pisoteamento; poluição por lixo; sujar e destruir os espeleotemas além da retirada para colocar em coleções particulares e mesmo em museus; pichações decorrentes da falta de conscientização ambiental; retirada de minérios; coletas de fauna exacerbada e mesmo de forma errada e destruição de sítios arqueológicos e paleontológicos devido a tentativas de retirada do material de formas inadequadas (KARNOPP et al, 2007; DONATO \& RIBEIRO, 2011).

São várias as cavernas brasileiras apresentando esse tipo de impacto, bem como cavernas sergipanas a exemplo da Toca da Raposa em Simão Dias com pichações e a Gruta Raposinha em Laranjeiras com seus espeleotemas quebrados.

O turismo pode causar diversos impactos negativos ao meio natural quando não há manejo, principalmente em ambientes subterrâneos (cavernas, grutas, furnas). As cavernas não são ambientes para visitação sem controle e em grande escala (PONTES et al, 2011).

Dessa forma, segundo Donato \& Ribeiro (2011), as cavernas com seus componentes bióticos e abióticos, seus minerais que são extremamente frágeis e interligados com o ambiente externo, estão à mercê de alterações ambientais, onde essas alterações mesmo sendo pequenas podem representar grandes ameaças à integridade dos ecossistemas cavernícolas. 
A visitação em cavernas seja para turismo, para práticas religiosas ou moradia, assim como praticamente todas as outras atividades humanas próximas a elas, concorrem para o afugentamento e aumento do estresse da fauna residente desses locais, diminuição da umidade relativa do ar e aumento do aquecimento do ar nos períodos em que ocorre a visitação (FERREIRA \& MARTINS, 2001 citado por DONATO \& RIBEIRO, 2011).

Há uma preocupação crescente com a preservação do patrimônio espeleológico, ocupando o centro das atenções dos espeleólogos brasileiros que através da Sociedade Brasileira de Espeleologia (SBE), conseguiram a inclusão da proteção espeleológica no novo texto constitucional, no qual se declara as cavernas como bens da União. Em junho de 1997 foi criado o Centro de Estudos, Proteção e Manejo das Cavernas (CECAV), vinculado ao Instituto Brasileiro de Meio Ambiente e Recursos Naturais Renováveis (IBAMA), por sua vez pertencente ao Ministério do Meio Ambiente (MMA), órgão ambiental federal do Brasil (KARNOPP et al, 2007).

Uma melhor compreensão do valor da conservação da natureza e da diversidade sóciocultural, priorizando a sensibilização do indivíduo quanto à importância do seu papel na construção de um mundo diferente, tanto na relação sociedade $\mathrm{x}$ natureza quanto à dos indivíduos entre si, foram objetivos almejados. O Espeleoturismo foi, portanto, utilizado como ferramenta para a Educação Ambiental (NEIMAN \& RABINOVICI, 2008).

Dessa forma, Donato \& Ribeiro (2011) afirmam que é necessário que essas atividades de espeleoturismo sejam muito bem conduzidas devido à grande fragilidade do sistema cavernícola. É possível a elaboração de planos de manejo espeleológicos e projetos de educação ambiental, a capacitação de guias locais e a conscientização de todos os envolvidos tornam-se essenciais para garantir o uso sustentável das cavernas.

Outra situação observada por Nunes et al (2008) é que nos últimos anos um público diferenciado tem sido atraído pela prática do turismo em áreas naturais, como os Portadores de Necessidades Especiais (PNEs). No entanto, para esse grupo tudo se torna um obstáculo devido à ausência de um design universal, que os inclua como participantes da sociedade. Desta forma, poucos ainda são os esforços destinados para garantir uma das mais crescentes formas de lazer no Brasil e no mundo para os PNEs: o turismo.

Nos termos do art. $2^{\circ}$ da Lei n. ${ }^{\circ} 10.098 / 2000$, acessibilidade é a possibilidade e condição de alcance para utilização, com segurança e autonomia, dos espaços, mobiliários e equipamentos urbanos, das edificações, dos transportes e dos sistemas e meios de comunicação, por pessoa portadora de deficiência ou com mobilidade reduzida (NUNES et al, 2008).

Acima de tudo, é fundamental investir na dissolução de barreiras arquitetônicas e sociais, que têm limitando ou restringido a descoberta de novas possibilidades de interação do portador de necessidade especial com a sociedade (NUNES et al, 2008).

Alem disso, os Parâmetros Curriculares Nacionais (PCN'S) sugerem para a educação de portadores de Necessidades Especiais a elaboração de propostas pedagógicas baseadas na 
interação com os alunos, a adoção de metodologias diferenciadas e motivadoras, a descoberta e a participação ativa no seu meio ambiente físico e social (BRASIL, 1997).

\section{MATERIAIS E MÉTODOS}

\section{Objeto e Estudo}

A caverna elegida para a produção da visita virtual foi a Toca da Raposa, cadastrada na Sociedade Brasileira de Espeleologia (SBE) com registro SE-002, e localizada na Fazenda Manoel Roque, uma propriedade particular do município de Simão Dias. Essa caverna constitui-se de quatro compartimentos morfológicos: um pequeno salão, logo após a entrada; um amplo salão alongado; uma ramificação de condutos labirínticos; e um salão final, totalizando 128,30 m de extensão (FERREIRA et al., 2009).

\section{Coleta de Dados}

As informações que constam no CD-ROM foram pesquisadas em livros, artigos científicos e resumos publicados em congressos.

As principais imagens que compuseram esse recurso didático foram fotografadas através de duas técnicas, comentadas por Morato (2009), a QuickTime Virtual Reality (QTVR) e Estereofotografia (3D). A QTVR consiste no uso de projeções esféricas de imagens panorâmicas que são montadas a partir de fotografias individuais. A Estereofotografia consiste na obtenção de duas imagens fotográficas tiradas a certa distância uma da outra e depois combinadas, dando uma noção de profundidade à cena (MORATO, 2009).

Para as imagens panorâmicas foi utilizada uma câmera Canon modelo PowerShot S5IS 8.0 megapixels (foi utilizado também nela o Conversion Lens Adapter LA-DC58E e o Wide Converter WC-DC58A para ampliar o campo de visão). Para cada imagem panorâmica utilizou-se um mínimo de 38 fotografias individuais, com algumas adicionais eventualmente para garantir a cobertura do chão. A montagem das imagens QTVR foram realizadas no programa PTGui (Photo stitching software 360 degree Panorama image software).

Para a confecção das estereofotografias, utilizou-se a câmera Fujifilm FinePix REAL 3D W3. Foram utilizados adaptadores da Cyclopital 3D para grande angular, com lentes Polaroid Studio Series $0.43 x$ Wide Angle Lens, e adaptador Cyclopital 3D para macrofotografias respectivamente para fotografias de salões ou detalhes, como para registro de invertebrados. A câmera gera arquivos no formato mpo, que podem ser visualizados apenas com equipamentos especialmente dedicados à projeção de imagens tridimensionais (como televisores e computadores com óculos próprios para tal fim). As imagens tridimensionais foram convertidas para anaglifos, criados através do programa StereoPhoto Maker, para poderem ser visualizadas 
em qualquer computador com o auxílio de óculos mais simples, com lentes de cor vermelho/ciano, que podem acompanhar o CD-ROM.

\section{Tratamento de Dados}

Após a obtenção e preparação das imagens, iniciou-se a construção do CD-ROM. Utilizouse o software Microsoft PowerPoint, versão 2007, para gerar uma apresentação do tipo tutorial, auto-explicativa, podendo ser utilizada tanto pelo aluno, sem auxílio de professor, como pelo próprio docente em sala de aula, como ferramenta de ensino (DONATO \& DANTAS, 2009). A mídia CD-ROM foi escolhida por suas facilidades de cópia e distribuição, com custo de reprodução muito baixo (CONDE et al., 2009).

\section{RESULTADOS E DISCUSSÃO}

O CD-ROM produzido foi intitulado "Conhecendo as cavernas de Sergipe - Toca da Raposa". Na apresentação do CD-ROM é possível ter acesso a sete tópicos: "O que é uma caverna?", "A Toca da Raposa", "Passeio virtual", "Fauna atual \& fóssil", "Publicações", "Matéria televisiva", e "Informações sobre o CD-ROM". Cada tópico foi desenvolvido para levar ao "visitante" um conhecimento do assunto de forma objetiva e acessível. As informações sobre cada item foram selecionadas e reescritas com uma linguagem clara, e as fotografias foram selecionadas auxiliando na visualização do ambiente, facilitando a interação com o mesmo.

O primeiro tópico, "O que é uma caverna?", apresenta informações gerais de como as cavernas são formadas, com imagens e fotografias. Através disso, poderá ser construída a ideia de como é o processo de formação das cavernas e quais elementos atuam nesse processo.

O segundo tópico, "A Toca da Raposa", cita informações sobre a caverna do estudo. Esse tópico mostra as características físicas da caverna, sua localização, ecossistema em que se encontra, clima, entre outras, para se entender o ambiente no qual ela está inserida.

O tópico "Passeio virtual" é o principal do CD-ROM, permitindo ao "visitante" fazer um tour virtual pela caverna. Em sua página principal, ele traz um mapa da caverna, onde estão dispostos cinco links, cada um em diferentes locais da caverna (Figura 1), mostrando fotos da entrada da caverna a partir do exterior, e de quatro salões.

Quando um desses ambientes é selecionado através de seu link ele dá acesso a imagens QTVR do ambiente (Figura 2) e 3D (Figura 3), de forma que é possível ter uma noção virtual da caverna. As estereofotografias apresentam elementos da fauna da caverna, ou de sua geomorfologia, enquanto as fotografias QVTR apresentam uma visão do ambiente como um todo, seja ele o externo à caverna, como no caso da entrada, ou interno, quando se apresenta detalhes da geomorfologia de cada salão. 
O quarto tópico, chamado "Fauna atual \& fóssil", foi divido em três categorias: vertebrados, invertebrados e fósseis. Em cada categoria foram apresentadas informações sobre alguns dos animais encontrados na caverna. Em "Vertebrados" temos informações sobre seis animais encontrados no ambiente: quatro espécies de morcegos (ordem Chiroptera) e dois anfíbios (Ordem Anura). Em "Invertebrados" encontramos imagens de quatro organismos: carrapato (Gênero Ornithodoros), pseudo-escorpião (Ordem Pseudoescorpiones), aranha marrom (Gênero Loxosceles) e barata (Periplaneta americana). E por fim temos "Paleofauna (fósseis)", categoria que descreve informações sobre duas espécies cujos fósseis foram encontrados nessa caverna, mas que representam animais que viveram fora dela e que foram preservados em sedimentos presentes no interior da cavidade.

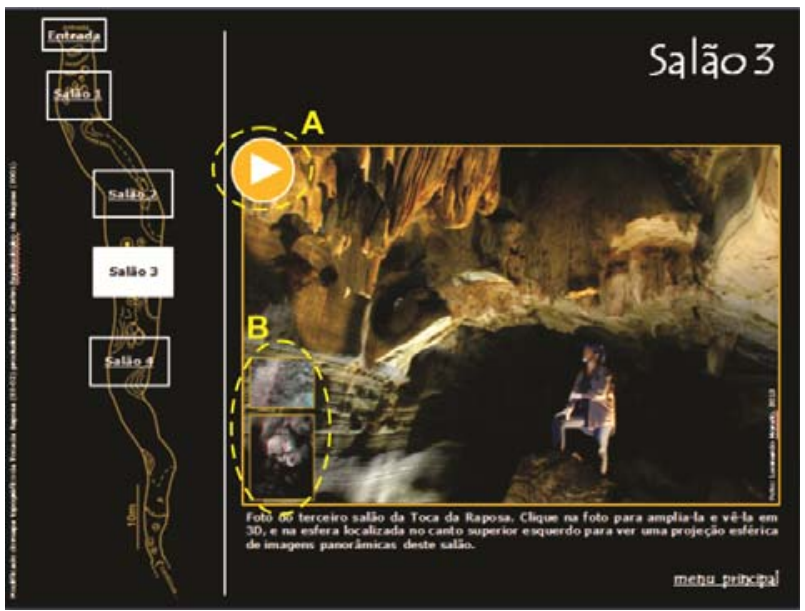

Figura 1: Tela do CD-ROM, mostrando as imagens que podem ser selecionadas em (A) QTVR e (B) 3D.

Esse tópico apresenta uma série de imagens que, quando selecionadas, apresentam textos com informações gerais, como nome científico, nomes populares, tamanho, distribuição, alimentação, comportamentos, entre outras. O objetivo é listar os representantes da fauna da caverna estudada.

O quinto tópico, "Publicações", tem os links de artigos completos, publicados em eventos nacionais e em periódicos científicos, sobre a Toca da Raposa, relacionados à Zoologia, Paleontologia e Ecologia. Esse tópico mostra o que já foi estudado e publicado sobre essa caverna.

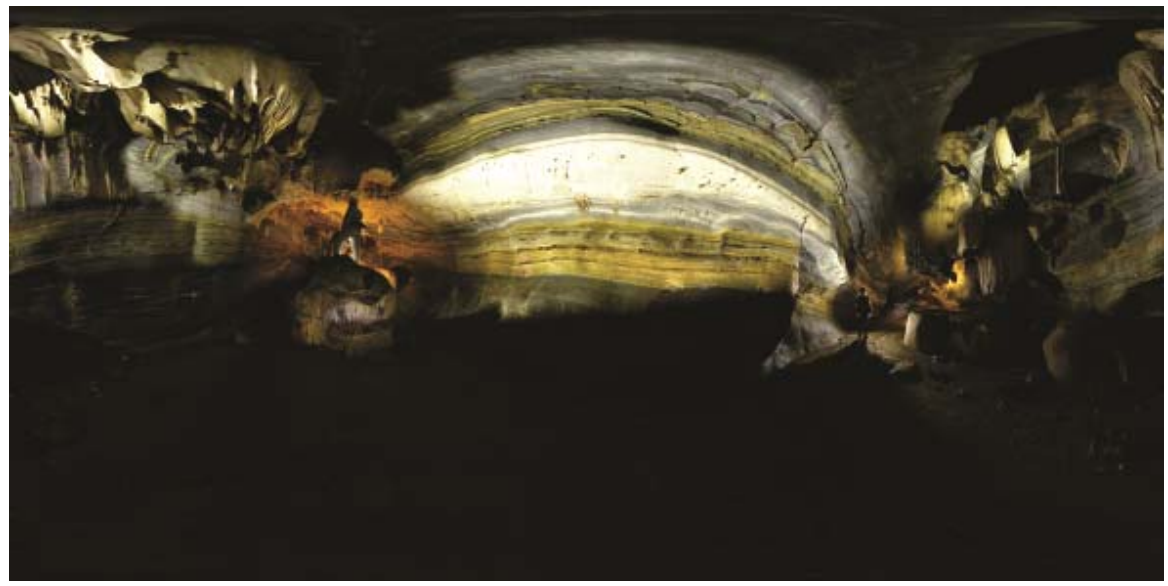

Figura 2: Imagem QTVR do Salão 3 da Toca da Raposa. 
No penúltimo tópico, "Matéria televisiva", é encontrado o vídeo da matéria sobre a Toca da Raposa, apresentada pelo programa Terra Serigy da TV Sergipe. Nele foram abordados alguns dos aspectos geológicos e biológicos da caverna, mostrando a importância da conservação e desmistificando várias pré-concepções sobre a mesma.

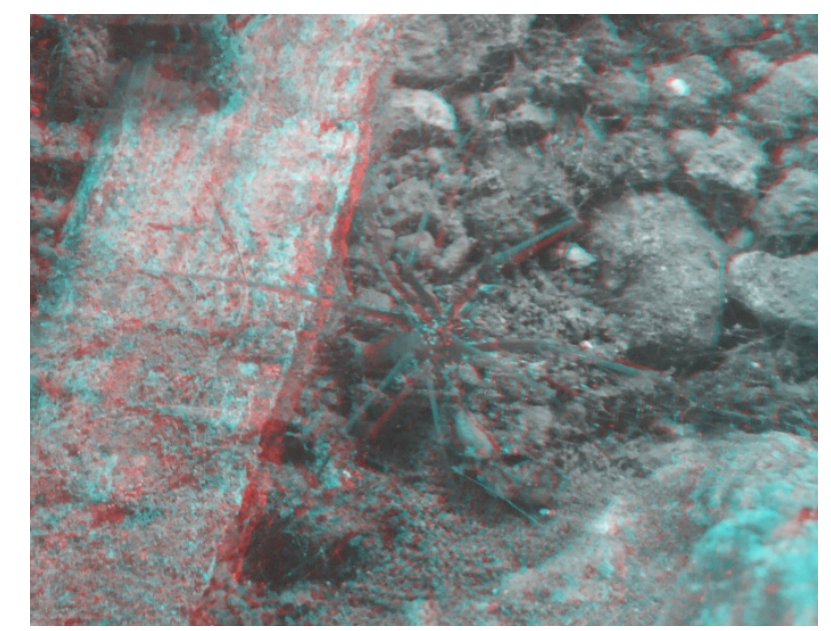

Figura 3: Imagem em 3D (anaglifo) de uma aranha marrom (Loxosceles sp.) encontrada na Toca da Raposa.

E, por fim, o ultimo tópico apresenta informações gerais sobre o CD-ROM, versão, e autores. No estado de Sergipe, Santana et al. (2010) verificaram 29 indicações sobre a existência de cavernas; destas, 24 estavam catalogadas junto à SBE, entre as mais de 10.134 cavidades presentes na base do Centro Nacional de Pesquisa e Conservação de Cavernas (CECAV) (GALVÃO \& CRUZ, 2012).

Em Sergipe, os estudos voltados à Espeleologia são recentes, se concentrando principalmente com a fauna de invertebrados (e.g., SANTANA et al., 2009, 2010; DONATO, 2011) e vertebrados cavernícolas (e.g., FERREIRA et al., 2009; DANTAS \& DONATO, 2011; DONATO et al., 2012) e com a flora do entorno e impacto ao patrimônio espeleológico (DONATO, 2011). Entretanto, a visitação desordenada e a prática de espeloturismo vêm ocorrendo de maneira imprópria nas cavernas sergipanas, nas quais não há plano de manejo e sua maioria não possui estudos ecológicos, de impacto ambiental e mesmo de capacidade de suporte para a visitação.

No Brasil as cavernas de cunho religioso foram as primeiras a receber um número significativo de visitantes, atraídos mais pela fé do que pela beleza estética (KARNOPP et al., 2007). Inúmeras cavernas brasileiras foram transformadas em santuários, especialmente na região central do país. Dentre as mais visitas, estão a Lapa do Bom Jesus, a Gruta Mangabeira e a Gruta dos Brejões, na Bahia, e a Terra Ronca em Goiás, com festas e romarias anuais (LINO, 2001).

Nos últimos anos, segundo Ferreira et al. (2008), os estímulos à visitação de cavernas no Brasil têm crescido consideravelmente. Existem incentivos do governo, do meio acadêmico e da sociedade, no intuito de promover uma maior difusão das atividades turísticas nos ambientes cavernícolas. 
Esses ambientes se distribuem por quase todo o país, porém apenas uma pequena parcela é explorada turisticamente. As mesmas são carentes de infraestrutura que permitam uma visitação adequada, o que evidencia a falta de planejamento prévio de melhor qualidade, que impede que o ecoturismo aconteça com real impacto educacional (KARNOPP et al., 2007).

Como componentes do relevo cárstico, as cavidades naturais subterrâneas possuem características bióticas e abióticas que as fazem atrativos ao uso antrópico (FERREIRA et al., 2008). Uma dessas características são os espeleotemas, formados basicamente por processos químicos de dissolução e precipitação mineral. São exemplos de espeleotemas as estalactites, estalagmites, colunas, flores minerais e uma infinidade de outros tipos, que recobrem tetos, pisos e paredes das cavernas, causando a admiração dos visitantes e frequentemente intrigando os pesquisadores (LINO, 2001). Essas formações ornamentam as cavidades, aumentando seu potencial turístico e por vezes religioso, dada a semelhança, no imaginário popular, de alguns espeleotemas com imagens sacras ou zoomórficas. A riqueza em espeleotemas coloca várias cavernas brasileiras entre as mais belas de todo o mundo, como a Gruta da Torrinha localizada na Chapada Diamantina, município de Iraquara, Bahia (KARNOPP et al., 2007).

O turismo, decorrente desse fascínio, tem grande potencial econômico, com capacidade de gerar renda e emprego nas localidades onde é desenvolvido, e tem sido visto como uma alternativa viável na utilização dos recursos naturais (DONATO \& RIBEIRO, 2011). Porém o espeleoturismo ainda é um campo recente de estudos dentro do espectro de possibilidades de planejamento, manejo e gestão do turismo em áreas naturais (LOBO \& MORETTI, 2009). Tornase evidente que as cavernas, como instrumento de visitação, são nichos pertencentes ao Ecoturismo, uma vez que o mesmo trata de uma modalidade do turismo cujo objetivo é a conservação do patrimônio ecológico, ou seja, a prática turística que tem por finalidade a implementação do uso racional do ambiente visitado (KARNOPP et al., 2007).

O espeleoturismo constitui, assim, uma forma de turismo de alto potencial educativo, desde que realizado de maneira adequada. Porém, o turismo pode ser responsável pela entrada de inúmeros materiais estranhos ao ambiente das cavernas, o que poderia ocasionar um forte desequilíbrio em seu ecossistema. Além disso, todas as instalações feitas nesses ambientes a fim de proporcionar a visitação, como escadas e iluminação artificial, também influenciam para o desequilíbrio ecológico interno, razão pela qual elas somente poderão ser efetuadas após um estudo prévio do impacto ambiental que poderiam causar (KARNOPP et al., 2007).

Entre os impactos gerados devido à visitação desordenada e ocasional através do turismo irregular, existem: acúmulo de restos de carbureto (utilizado como fonte de luz) e lixo diverso dentro das cavernas; pisoteamento de espeleotemas e fauna; depredação de espeleotemas, com sujeira ou retirada para coleções particulares e mesmo em museus; pichações decorrentes da falta de conscientização ambiental; coletas de fauna e destruição de sítios arqueológicos e paleontológicos devido a tentativas de retirada do material de formas inadequadas (KARNOPP et al., 2007; DONATO \& RIBEIRO, 2011). 
São várias as cavernas brasileiras apresentando esses tipos de impactos, bem como as sergipanas, a exemplo da Toca da Raposa em Simão Dias, com pichações, lixo e depredações, e a Gruta Raposinha em Laranjeiras, com seus espeleotemas quebrados (AULER \& ZOGBI, 2005; DONATO, 2011). O turismo pode causar impactos negativos ao meio natural quando não há manejo, principalmente em ambientes subterrâneos. As cavernas não são ambientes para visitação sem controle e em grande escala (PONTES et al., 2011).

Dessa forma, segundo Donato \& Ribeiro (2011), as cavernas com seus componentes bióticos e abióticos, interligados ao meio externo, estão à mercê de alterações ambientais, em que essas, mesmo pequenas, podem representar graves ameaças à integridade dos ecossistemas cavernícolas. A visitação em cavernas, seja para turismo, práticas religiosas ou moradia, assim como praticamente todas as outras atividades humanas próximas a essas, concorrem para o aumento do estresse e eventual afugentamento da fauna residente desses locais, diminuição da umidade relativa do ar e aumento de temperatura nos períodos em que ocorre a visitação (FERREIRA \& MARTINS, 2001 citado por DONATO \& RIBEIRO, 2011).

Dessa forma, Donato \& Ribeiro (2011) afirmam que é imprescindível que as atividades de Espeleoturismo sejam muito bem conduzidas. É necessária não só a elaboração de planos de manejo espeleológicos, como projetos de educação ambiental, a capacitação de guias locais e a conscientização de todos os envolvidos para garantir o uso sustentável das cavernas. Há uma preocupação crescente com a conservação do patrimônio espeleológico, ocupando o centro das atenções dos espeleólogos brasileiros que, através da SBE, conseguiram a inclusão da proteção espeleológica no novo texto constitucional, no qual se declara as cavernas como bens da União (KARNOPP et al., 2007). Uma melhor compreensão do valor da conservação da natureza e da diversidade sociocultural, priorizando a sensibilização do indivíduo quanto à importância do seu papel na construção de um mundo diferente, tanto na relação sociedade versus natureza, quanto à dos indivíduos entre si, foram objetivos almejados. O Espeleoturismo é, nesse cenário, visto como ferramenta para a Educação Ambiental (NEIMAN \& RABINOVICI, 2008).

Outra situação observada por Nunes et al. (2008) é que, nos últimos anos, um público diferenciado tem sido atraído pela prática do turismo em áreas naturais, incluindo pessoas com necessidades especiais (PNE's). No entanto, para esse grupo existem muitos obstáculos devido à ausência de um design universal, que os inclua como participantes da sociedade. Dessa forma, poucos ainda são os esforços destinados para garantir uma das mais crescentes formas de lazer no Brasil e no mundo para as PNE's, o turismo.

Nos termos do art. $2^{\circ}$ da Lei n. ${ }^{\circ} 10.098 / 2000$ (BRASIL, 2000), acessibilidade busca garantir a possibilidade e condição de alcance para utilização, com segurança e autonomia, dos espaços, mobiliários e equipamentos urbanos, das edificações, dos transportes e dos sistemas e meios de comunicação, por pessoa com necessidades especiais ou com mobilidade reduzida. Acima de tudo, é fundamental investir na dissolução de barreiras arquitetônicas e sociais, que têm limitado 
ou restringido a descoberta de novas possibilidades de interação dessas pessoas com a sociedade (NUNES et al., 2008).

Nessa perspectiva, a construção de um CD-ROM como ferramenta de turismo virtual insere-se na adequação de metodologias que auxiliem às PNE's uma experiência de Espeleoturismo em cavidades que não possuam adaptações para a acessibilidade desse público, ou plano de manejo.

\section{CONSIDERAÇÕES FINAIS}

Este trabalho possibilita uma forma de turismo virtual. As técnicas utilizadas para a confecção das imagens, com a imersão alcançada com as estereofotografias e as fotografias panorâmicas esféricas, consideraram a acessibilidade, de modo que em qualquer lugar pessoas poderão conhecer um pouco desse ambiente cavernícola, ao mesmo tempo em que as cavernas são mantidas conservadas. O CD-ROM oportuniza a diminuição de visitas desordenadas a cavernas onde ainda não foram realizados estudos de capacidade de carga e plano de manejo, em paralelo à conscientização da importância desses ecossistemas com o acesso a informações pertinentes sobre a caverna, abrindo espaço também para divulgar a Ciência Espeleologia e possibilitar que pessoas que teriam dificuldades para visitar estes ambientes consigam de forma interativa e segura.

\section{REFERÊNCIAS}

BRASIL. Decreto $n^{\circ}$ 5.296, de 2 de dezembro de 2004. Regulamenta as Leis $n^{\circ \mathrm{os}} 10.048$, de 8 de novembro de 2000 , que dá prioridade de atendimento às pessoas que especifica, e 10.098 , de 19 de dezembro de 2000, que estabelece normas gerais e critérios básicos para a promoção da acessibilidade das pessoas portadoras de deficiência ou com mobilidade reduzida, e dá outras providências. Brasília: DOU, 2004.

BRASIL. Lei no 10.098, de 19 de dezembro de 2000. Estabelece normas gerais e critérios básicos para a promoção da acessibilidade das pessoas portadoras de deficiência ou com mobilidade reduzida, e dá outras providências. Brasília: DOU, 2000.

BRASIL. Lei $\mathbf{n}^{\circ} \mathbf{7 . 8 5 3}$, de 24 de outubro de 1989. Dispõe sobre o apoio às pessoas portadoras de deficiência, sua integração social, sobre a Coordenadoria Nacional para Integração da Pessoa Portadora de Deficiência - Corde, institui a tutela jurisdicional de interesses coletivos ou difusos dessas pessoas, disciplina a atuação do Ministério Público, define crimes, e dá outras providências. Brasília: DOU, 1989.

BRASIL. Parâmetros Curriculares Nacionais Ensino Médio. Brasília, 1998.

CONDE, S. J.; ISHARA, K. L.; NISHIDA, S. M.; DINI, R. E. S.. Proposta de CD-ROM sobre comportamento sexual dos animais para a disciplina de Biologia do Ensino Médio. 2003.

DANTAS, M. A. T.; DONATO, C. R.. Registro de Lontra longicaudis (Olfers, 1818) na caverna da Pedra Branca, Maruim, Sergipe, Brasil. Scientia Plena. v.7, n.8, p.1-4, 2011.

DONATO, C. R.. Análise de impacto sobre as cavernas e seu entorno no Município de Laranjeiras, Sergipe. 2011. 198 p. Dissertação (Mestrado em Desenvolvimento e Meio Ambiente). Universidade Federal de Sergipe, São Cristóvão, 2011. 
DONATO, C. R.; DANTAS, M. A. T.. CD-ROM como instrumento de aprendizagem significativa sobre a Bioespeleologia Sergipana. Revista Electrónica de Investigación em Educación en Ciencias, v.4, n.2. p.39-47, 2009.

DONATO, C. R.; DANTAS, M. A. T.; ROCHA, P. A.. Epicrates cenchria (Rainbow Boa): Diet and foraging behavior. Herpetological Review. v.43, p.343-344, 2012.

DONATO, C. R.; RIBEIRO, A. S.. Caracterização dos impactos ambientais de cavernas do município de Laranjeiras, Sergipe. Caminhos da Geografia, Uberlândia, v.12, n.40, p.243-255, 2011.

FERREIRA, A. S.; DANTAS, M. A. T.; DONATO, C. R.. Ocorrência de Leptodactylus vastus Lutz, 1930 (AMPHIBIA-ANURA: LEPTODACTYLIDAE) na caverna Toca da Raposa, Simão Dias, Sergipe. In: Congresso Brasileiro de Espeleologia, 30, 2009. Anais. Belo Horizonte, 2009.

FERREIRA, R. L.; MARTINS, R. P.. Cavernas em risco de extinção. Ciência Hoje, v.29, n.173, p.20-28. 2001.

FERREIRA, R. L.; GOMES, F. T. M. C.; SILVA, M. S.. Uso da cartilha "Aventura da vida nas cavernas" como ferramenta de educação nas atividades de turismo em paisagens cársticas. Pesquisas em Turismo e Paisagens Cársticas, Campinas, v.1, n.2, p.145-164, 2008.

GALVÃO, A. L. C. O.; CRUZ, J. B.. Brasil ultrapassa 10.000 cavernas conhecidas. ESPELEOINFO, v.3, p.18, 2012.

KARNOPP, P. K. F.; ANDRETTA, V.; MACEDO, R. L.G.; VITORINO, M. R.; MACEDO, S. B.; VENTURINI, N.. Espeleologia: um instrumento de difusão da educação ambiental em atividades ecotúristicas. In:

Congresso Nacional de Ecoturismo, 4. Anais. Itatiaia, 2007.

LINO, C. F.. Cavernas: o fascinante Brasil Subterrâneo. 2 ed. São Paulo: Gaia, 2001.

LOBO, H. A. S.; MORETTI, E. C.. Sustentabilidade Ecológica do Espeleoturismo na Serra da Bodoquena, Mato Grosso do Sul. Turismo em Análise, v.20, n.1, p.151-167, 2009.

MORATO, L. Quicktime Virtual Reality e Estereofotografia: utilizando técnicas fotográficas imersivas para a divulgação da Espeleologia no Brasil. In: CONGRESSO BRASILEIRO DE ESPELEOLOGIA. 30, 2009.

Anais. Minas Gerais, p.151-158, 2009.

NEIMAN, Z.; RABINOVICI, A.. Espeleoturismo e educação ambiental no PETAR. Pesquisas em Turismo e Paisagens Cársticas, Campinas, v.1, n.1, p.57-65, 2008.

NUNES, E.; LUZ, C. S.; ANJOS, D. T.; GONÇALVES, A. C.; FIGUEIREDO, L. A. V.; ZAMPAULO, R. A.. Inclusão social de Portadores de Necessidades Especiais (PNEs) e a prática do turismo em áreas naturais: avaliação de seis cavidades turísticas do Estado de São Paulo. Pesquisas em Turismo e Paisagens Cársticas, Campinas, v.1, n.1, p.77-88, 2008.

PONTES, H. S.; MASSUQUETO, L. L.; FILHO, J. C. F.. Educação Ambiental em ambientes subterrâneos. Estudo de caso na Gruta Olhos D'água, município de Castro - PR. In: ENCONTRO PARANAENSE DE EDUCAÇÃO AMBIENTAL. 13, 2011. Anais. Curitiba, 2011.

RODRIGUES, B. E. P. F.. Espeleologia no ensino fundamental: contribuições da pedagogia waldorf para a educação ambiental e o ecoturismo. In: CONGRESSO BRASILEIRO DE ESPELEOLOGIA, 29. Anais. Belo Horizonte, p.121-128, 2007.

SANTANA, M. E. V.; SOUTO, L. S.; DANTAS, M. A. T.. Diversidade de invertebrados cavernícolas na Toca da Raposa (Simão Dias - Sergipe): o papel do recurso alimentar e métodos de amostragem. Scientia Plena. v.6, n.12, p.1-8, 2010.

SANTANA, M. E. V.; SOUTO, L. S.; DANTAS, M. A. T.; DONATO, C. R.; OLIVEIRA, D. M.. Levantamento da fauna de invertebrados cavernícolas na Toca da Raposa, Simão Dias, Sergipe, Brasil - Resultados preliminares. In: CONGRESSO BRASILEIRO DE ESPELEOLOGIA. 30. Anais. Belo Horizonte, 2009. 